\author{
Domenico D'Amico \\ Giuseppe Libro \\ Maria Pia Prudenzano \\ Cesare Peccarisi \\ Mario Guazzelli \\ Giuliano Relja \\ Francomichele Puca \\ Sergio Genco \\ Ferdinando Maggioni \\ Giuseppe Nappi \\ Anna Pia Verri \\ Rosanna Cerbo \\ Gennaro Bussone
}

\section{Stress and chronic headache}

\author{
D. D’Amico • G. Libro • C. Peccarisi • \\ G. Bussone (凶) \\ C. Besta National Neurological Institute \\ Via Celoria 11, I-20133 Milan, Italy \\ e-mail: bussone@istituto-besta.it \\ Tel.: +39-02-2394264 \\ Fax: +39-02-70638067
}

The affiliations of the other authors are listed at the end of the article

\begin{abstract}
The aims of this study were to assess how stress affects chronic headaches, and in particular to determine whether events play a role in the transformation of an episodic headache into a chronic form. A population of 267 Italian patients with chronic headache (headache present on average more than 15 days per month) was studied. Our results confirm a triggering role of stress on headache. We also found that episodic headache (migraine in most patients, $74.1 \%$ ) preceded the development of a
\end{abstract}

chronic form in about $90 \%$ cases. Among these patients, in $44.8 \%$ a stressful event correlated with the transformation. Analysis of these events revealed that minor events played a greater role than major life events, suggesting that patients with transformed headache are characterised by a different way of reacting to stress.

Key words Chronic headache • Stress $\cdot$ Life events $\cdot$ Trigger factor • Migraine $\cdot$ Transformation of headache

\section{Introduction}

It is a matter of clinical experience that psychological factors, in particular stress, can exert notable effects on primary headaches. Several studies have shown that stress is one of the most common trigger factors for headache, both in migraine and in tension-type headache [1-5]. It is reasonable, therefore, that stress may exert effects on the clinical evolution of these headaches. For example, stressful events may increase headache frequency or promote transformation of an episodic headache into a chronic form. A chronic headache is one present on average more than 15 days per month [6]. A transformed headache is an originally episodic headache that developed into a chronic one.

A stressful event is an environmental situation or psychological trauma that compromises or threatens wellbeing. Several models have been proposed to explain how stress can influence headache. More recent theories do not consider stress as a purely exogenous factor but recognise that stressful events can induce objective biological and psychological changes.

Stress acts on the body via the endocrine system, autonomic nervous system and immune system [7-9]. These systems act as biological integrators in the body, functioning to maintain homeostasis. In turn they are influenced by such factors as genetic makeup or constitution, psychobiological imprinting and the external environment (the sum of physical, emotional and social stimuli). Stressful events affect the brain through inputs from the cortex, subcortical regions, and sensory organs, and from the endocrine system, provoking reactions mediated, principally, by the hypothalamo-hypophyseal-adrenal axis (CRH) and by the locus coeruleus (norepinephrine). The effects of these multifarious hormonal and neurotransmitter changes vary with the duration of the stressful stimulus. Prolonged and repeated exposure to stressful stimuli may lead to permanent functional changes and even to anatomical damage, and can thus assume the role of a pathogenetic agent or illness precursor. 
Prolonged stress has been shown to induce functional lesions in the nerve terminals within the hypothalamus and locus coeruleus in animals [10]. Prolonged glucocorticoid secretion (as occurs in chronic stress) may be responsible for loss of hippocampal dendrites or neurons in humans [11].

Lazarus and Folkman proposed the transactional model of stress which focuses on cognitive aspects [12]. They distinguished two types of evaluation of stressful events: primary evaluation, whether an event is interpreted to be significant to the person's wellbeing; and secondary evaluation, whether the person has the resources available to respond successfully to the event. If an event is judged to be a threat, then a coping response is required; unsuccessful attempts at coping lead to physiologic arousal and eventually to pain (for example, through muscle tension).

\section{Patients and methods}

The aims of the study were to determine to what extent stress adversely affected chronic headache, to identify patients whose chronic headache had developed from an episodic form, and to investigate whether stress played a role in that transformation.

The study was conducted on out-patients recruited consecutively at the main Italian headache centres. Inclusion criteria were chronic headache (pain for 15 or more days per month for at least six months) and age between 18 and 65 years. A total of 267 patients were enrolled. Patients were interviewed individually and data were entered directly onto a computer form that had been designed for the study. Stressful events reported by patients were classified according to Paykel et al.'s life events scale [13] and grouped into 10 activity areas, as reported in the Italian translation of the scale [14]: work, education, finances, health, bereavement, migration, courtship and cohabitation, legal concerns, family and social issues, and marriage

\section{Results}

Of the 267 chronic headache patients enrolled, only 28 had chronic headache from onset. In the remaining $239(89.5 \%)$ cases, the headache had developed from an episodic headache. In 177 (74.1\%) of 239 patients, the initial headache was migraine, and in $34(14.2 \%)$ the headache was tension type (Table 1).

Regarding stress as a headache aggravating factor, we found that $120(44.9 \%)$ patients reported a deterioration of their chronic headache following a stressful event.

Among the 239 patients in whom an originally episodic headache had become chronic, stress was reported to be a trigger for the episodic headache in 87 (36.4\%) cases. Furthermore, 107 (44.8\%) of these patients indicated that a stressful event correlated with the passage from episodic to chronic headache (Table 2). Stressful events were due to health problems in $35.6 \%$ of cases, family and social problems in $17 \%$ of cases, marriage in $13.6 \%$, bereavement in $13.6 \%$, and work in $11.4 \%$. Less frequently, legal concerns, education, courtship and cohabitation, finances and migration-related problems were mentioned (Fig. 1).

We conducted a further analysis to determine whether major stressful events, such as serious illness or loss of job, had greater effect than minor events on headaches.

Table 1 Initial headache diagnosis in 267 chronic headache patients

\begin{tabular}{lrl}
\hline Diagnosis at onset & Patients, $\mathrm{n}(\%)$ \\
\hline Chronic headache & 28 & $(10.5)$ \\
Episodic headache & 239 & $(89.5)$ \\
Migraine & $177 \quad(74.1)^{\mathrm{a}}$ \\
Migraine + tension-type headache & 5 & $(2.1)^{\mathrm{a}}$ \\
Tension-type headache & $34 \quad(14.2)^{\mathrm{a}}$ \\
Not classifiable headache & $23 \quad(9.6)^{\mathrm{a}}$ \\
Total & $267 \quad(100)$ \\
\hline
\end{tabular}

a Percent of 239 patients initially diagnosed with episodic headache

Table 2 Presence of life events associated in time with the transformation of headache from an episodic to a chronic form

\begin{tabular}{lc}
\hline Chronic headache patients with an episodic headache at onset & Patients, $\mathrm{n}(\%)$ \\
\hline With presence of life events & $107(44.8)$ \\
With absence of life events & $132(55.2)$ \\
Total & $239(100.0)$ \\
\hline
\end{tabular}


Fig. 1 Life events and transformation from episodic to chronic headache

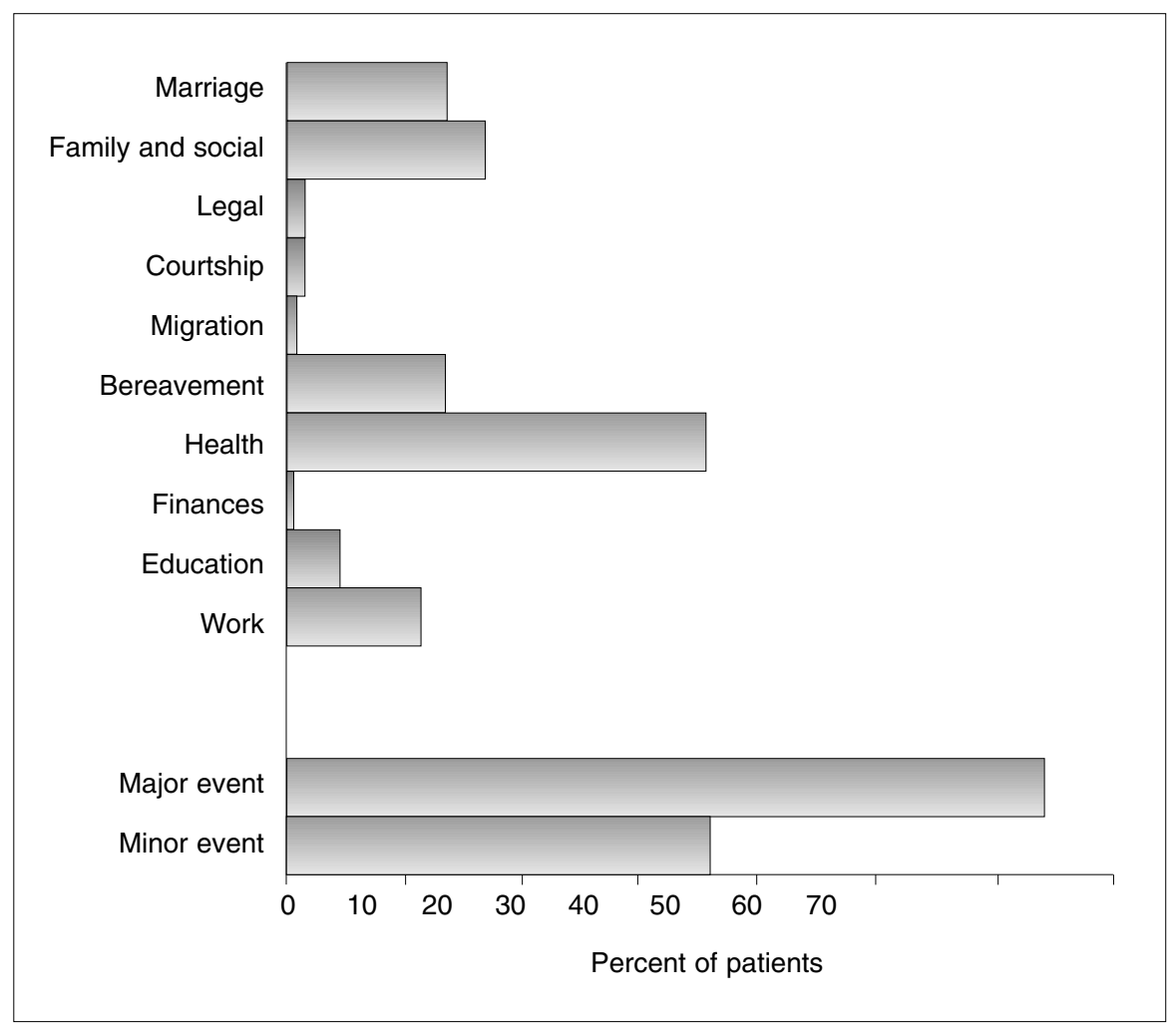

Minor events were those related to the following areas of Paykel et al.'s scale: courtship and cohabitation, marriage, education, family/social; and paraphysiological health problems (e.g. menopause, birth of a child, use of oral contraceptives) and non-serious work problems (stressful relationships and work conditions). Major problems were bereavement, financial troubles, legal concerns, and migration from Paykel et al.'s activity areas, and serious illness or work problems (e.g. change or loss of job and retirement).

Of the patients in whom chronic headache had developed from episodic headache, $154(64.4 \%)$ reported that a minor stressful event coincided with this change, while only $85(35.6 \%)$ indicated that a major event coincided with the change (Fig. 1).

\section{Discussion}

This study has confirmed the hypothesis that stress has a negative influence on headache. Specifically, we found that stress leads to a worsening of chronic headaches and acts as a trigger of episodic headache attacks before they transform into chronic headaches. We also found that in almost $90 \%$ of cases the chronic headache was originally episodic in nature, but at some point transformed into a chronic form.
Furthermore, in most cases the original episodic headache was migraine. These findings are in accord with previous studies [15, 16], one of which [15] first proposed the term "transformed" to refer to migraine that had become chronic. Our data, in addition, indicate the existence of a relation between stress and this transformation process: stressful events were associated in time with the transformation of the headache in $44.8 \%$ of patients.

Patients with headache may either be more exposed to stressful psychosocial stimuli, or have reduced ability to tolerate stress. Published findings regarding the former hypothesis are not clear cut. For example, Invernizzi et al. [17] reported more stressful life events in a group of primary headache patients than in healthy controls. However, when the diagnostic categories were considered it emerged that the significant difference was due entirely to patients with migraine, while patients with chronic headaches ("mixed" and "daily" headaches) did not differ from controls. De Benedictis and Lorenzetti [18] studied patients with recurrent headache (average frequency, 16 days $(\mathrm{SD}=10)$ per month) and found that those with chronic tension-type headache and "mixed" headache were more exposed to stressful events than controls or migraine patients. Here, however, the significant differences pertained to "daily hassles" - small problems of daily life - and not major life events.

The second idea, that patients whose headaches have 
become chronic cope poorly with stress, seems more likely from published work. Holm et al. [19] found that patients with tension chronic-type headache judged stressful events more negatively than controls and this difference was more evident for daily hassles. Furthermore, these patients adopted less efficient coping strategies, using mainly avoidance behaviour and self criticism, while seeking less social support. Martin and Theunissen [20] found no difference between high frequency migraineurs, tension-type headache patients and controls as regards frequency and importance of life events. However, there were significant differences on measures of social support: patients could count on fewer people for emotional and social support, and these were less useful.

Our findings also indicate that minor events (which we call daily hassles) play a greater role in transforming headache than major events (as we defined them), suggesting that patients with transformed headache are characterised, not by greater exposure to major stressful events, but by a different way of reacting to stress.
M.P. Prudenzano • F. Puca • S. Genco

Neurological Clinic I,

University of Bari, Bari, Italy

M. Guazzelli

Psychiatric Clinic,

University of Pisa, Pisa, Italy

F. Maggioni

Neurological Clinic,

University of Padua, Padua, Italy

G. Nappi • A.P. Verri

IRCCS Mondino,

University of Pavia, Pavia, Italy

R. Cerbo

Department of Neurological Sciences

University of Rome La Sapienza, Rome, Italy

G. Relja

Ospedale Maggiore, Trieste, Italy

\section{References}

1. Passchier J, Andrasik F (1993)

Tension-type headache, cluster headache, and miscellaneous headaches: Psychological factors. In: Olesen J, Tfelt-Hanson P, Welch KMA (ed) The headaches. Raven, New York, pp 233-240 (Chapt. 13)

2. Andrasik F, Passchier J (1993) Tension-type headache, cluster headache, and miscellaneous headaches: psychological aspects. In: Olesen J, Tfelt-Hanson P, Welch KMA (ed) The headaches. Raven, New York, pp 489-492 (Chapt. 70)

3. Andrasik F, Holroyd KA, Abell T (1979) Prevalence of headache within a college student population: a preliminary analysis. Headache 19:384-387

4. Henryk-Gutt R, Rees WL (1973) Psychological aspects of migraine. J Psychosom Res 17:141-153

5. Mosley TH, Penzien DB, Johnson CA, Brantley PJ, Wittrock DA, Andrew ME, Payne TJ (1991) Time series analysis of stress and headache. Cephalalgia 11[Suppl 11]:306-307

6. Headache Classification Committee of the International Headache Society (1988) Classification and diagnostic criteria for headache disorders, cranial neuralgias and facial pain. Cephalalgia 8[Suppl 7]:1-96
7. Bussone G, Leone M (1990) Ambiente, reattività psicobiologica $\mathrm{e}$ cefalea. Le cefalee primarie come possibile disordine dei processi psicobiologici adattativi. Federazione Medica XLIII (2):99-103

8. Stratakis CA, Chrousos GP (1995) Neuroendocrinology and pathophysiology of the stress system. Ann N Y Acad Sci 771:1-18

9. Pietrini P, Guazzelli M (1997) Life events in the course of chronic diseases: A psychological myth or a psycho-neuro-biochemical loop? Clin Exp Rheum 15:125-128

10. Weiss JM, Bailey WH, Goodman PA, Hoffman LJ, Ambrose MJ, Salman S, Charry JM (1982) A model for neurochemical study of depression. In: Spiegelstein MY, Levy A (eds) Behavioral models and the analysis of drug action. Elsevier, Amsterdam, pp 195-223

11. Sapolsky RM (1996) Why stress is bad for your brain. Science 273:749-750

12. Lazarus RS, Folkman S (1984) Coping and adaptation. In: Gentry WD (ed) The handbook of behavioral medicine. Guilford, New York
13. Paykel ES, Prusoff BA, Uhlnhuth EH (1971) Scaling of life events. Arch Gen Psychiatry 25:340-347

14. Fava GA, Osti RMA (eds) (1981) Scala di Paykel per gli eventi stressanti, versione Italiana. OS Organizzazioni Speciali, Florence

15. Mathew NT, Reuveni U, Perez F (1987) Transformed or evolutive migraine. Headache 27:102-106

16. Silberstein SD, Lipton RB, Sliwinski M (1996) Classification of daily and near daily headaches: field trial of revised IHS criteria. Neurology 47:871-875

17. Invernizzi G, Gala C, Sacchetti E (1985) Life events and headache. Cephalalgia 5[Suppl 2]:229-231

18. De Benedictis G, Lorenzetti A (1992) The role of stressful life events in the persistence of primary headache: major events vs. daily hassles. Pain 51:35-42

19. Holm JE, Holroyd KA, Hursey KG, Penzien DB (1986) The role of stress in recurrent tension headache. Headache 26:160-167

20. Martin PR, Theunissen C (1993) The role of life event stress, coping and social support in chronic headaches. Headache 33:301-306 